\title{
Development of linear model for leaf area measurement of two medicinally important plants: Helicteres isora L. and Vitex negundo L.
}

\author{
Nancy R. Kumbhani, Ranjan P. Kuvad, Vrinda S. Thaker* \\ Plant Physiology and Molecular Biology Lab Department of Biosciences, Saurashtra University, Rajkot-360 005, Gujarat, India.
}

\section{ARTICLE INFO}

Article history:

Received on: 07/09/2016

Accepted on: 03/05/2017

Available online: 19/06/2017

\section{Key words:}

Helicteres isora L., Vitex

negundo L., Gravimetric

parameters, Leaf area, Regression

coefficient.

\begin{abstract}
Leaf area is an important parameter in physiological and agronomical studies. Linear models for leaf area measurement were developed for two plant species as a non destructive method. The leaves of Helicteres isora $L$. and Vitex negundo $L$ were used for the linear model development using Leaf Area Meter (LAM) software.Gravimetric (dry weight and water content) parameters were considered for the development of linear model for these plants species which showed statistically significant relationship with the parameters studied. The best correlation as represented by regression coefficient $\left(\mathrm{R}^{2}\right)$ was used. It was observed that with increase in leaf area, dry weight and water content also increased and showed best correlation with the leaf area. Thus, it was concluded dry weight and water content can be taken as a parameter for developing linear model for leaf area in these plants.
\end{abstract}

\section{INTRODUCTION}

Helicteres isora L. is a large shrub of the family Sterculiaceae which occurs in dry forests throughout central and western India and some parts of the south-east Asia. The plant gained its name as Indian Screw Tree due to the characteristic twisted shape of its fruits [1]. Different parts of the plant are traditionally used in Indian System of Medicine (ISM) to cure various ailments. Furthermore, recent research results have suggested that $H$. isora was a rich source of bioactive compounds such as polyphenols, tannins and alkaloids that exhibit therapeutic effects [2]. H. isora is reported to be a good source of carbohydrate, proteins, fiber, calcium, phosphorus and iron [3]. Another report based on extraction and characterization studies had shown the presence of some antioxidant compounds such as ascorbic acid, flavonoids and phenolics (cucurbitacin B and isocucurbitacin B) [4,2]. Vitex negundo L. is a woody, aromatic deciduous shrub growing to a small tree. It is also known as the five-leafed chaste tree or Monk's pepper [5]. The leaves have five leaflets palmately arranged, which are lanceolate, hairy and pointed at both ends [6]. The leaves have potential for

* Corresponding Author

Email: thakervs @ gmail.com,

Phone No.: 91-9687692945, Fax No. 91-281-22576419 antibacterial, antitumor, astringent, tonic, vermifuge, antiparasiticaland insect repellent. Anti-inflammatory and pain suppressing activities of fresh leaves of $V$. Negundo are attributed to prostaglandin synthesis inhibition, membrane stabilizing and antioxidant activities [7]. Leaf area of the plants not only determines the photosynthetic capacity but can also be used as a morphological marker for collection of medicinally important plants [8,9]. Leaf area of the plants is correlated with leaf dimensions like length and width and linear models are developed as non-destructive method. Further, gravimetric parameters like leaf dry weight can also be used to build linear model for leaf area [10]. These plants have great potential to be developed as drugsin pharmaceutical industries. However, herbal formulations are often questioned for their consistency mainly because less care is taken during the production of herbal medicines. Physiologically active compounds may vary with age and conditions of the leaves. Therefore, there must be some guide lines for the collection of such materials. Leaf area (LA) is an important variable for most ecophysiological studies in terrestrial ecosystems concerning light interception, evapotranspiration, photosynthetic efficiency, fertilizers, irrigation response and plant growth [11] and hence, also to maintain herbal farms with efficient practices. Both these plants are having immense herbal drug applications and the development of linear model for these plants may help the researchers of the field. 


\section{MATERIALS AND METHODS}

\subsection{Collection of plant materials}

Helicteres isora $\mathrm{L}$. leaves were collected from Laldhori Garden of Junagadh Agriculture University and leaves of Vitex negundo L. were collected from Botanical garden of Saurashtra University campus, Rajkot, Gujarat.

\subsection{Measurement of growth parameter}

Collected leaves were washed thoroughly under running tap water and blotted over filter papers. Each individual leaf/leaflets were scanned and saved as .bmp file format. The scanned leaf was weighed before and after oven drying at $65^{\circ} \mathrm{C}$ for 48 hours to obtain the dry weight. The difference in fresh and dry weight is considered as the water content. Each individual leaf/leaflets was scanned and saved in .bmp file format and then leaf area measurement was calculated as per the software's standard protocol $[8,9]$. The present method of leaf area measurement is very simple, rapid as software (LAM) is very efficient and user friendly [31]. This software measures different parameters of leaf (leaf area, length of midrib and width of leaf) similar measurements can be done using image $\mathrm{J}$ software [12].

\subsection{Statistical Analysis}

All collected data were subjected to regression analysis, linear correlations between leaf area and gravimetric parameters using Excel software (MS office, Microsoft).

\section{RESULTS AND DISCUSSION}

Medicinal plants are of prime focus in alternative medicine worldwide. Leaves of many plants have been used as a source of medicine. Age of the plants, which are selected for producing herbal formulations, is needed to be considered for the higher yield of the desired active compounds, which may influence the efficacy of the medicine [8,9]. Growth in the terms of fresh and dry weights, water content and leaf area of each individual leaf were measured from both the plants studied (Figure: 1,2).

From $H$. isora plant, 45 leaves were taken for the leaf area measurements by using leaf area measurement software which showed ranged between 1 to $45.8 \mathrm{~cm}^{2}$ areas for the leaves tested. Minimum leaf area was observed $1.0 \mathrm{~cm}^{2} /$ leaf where as maximum leaf area was $45.8 \mathrm{~cm}^{2} /$ leaf. Each individual leaf was weighed before and after oven drying at $65^{\circ} \mathrm{C}$ for constant weight. Dry Weight ranged between 20.2 to $182.5 \mathrm{mg} / \mathrm{leaf}$. Water Content ranged between 7.1 to $390.8 \mathrm{mg} / \mathrm{leaf}$. The obtained data on dry weights and water content were plotted against respective leaf area showed linear relationship (Figure 1: A, B). Similarly, in $V$. Negundo leaf area ranged between 3.27 to $27.50 \mathrm{~cm}^{2} /$ leaf from the 49 leaves tested. Data on dry weight ranged between 27.3 to179.7 $\mathrm{mg} / \mathrm{leaf}$ and data on water content ranged between 54.8 to 352.3 $\mathrm{mg} / \mathrm{leaf}$ (Figure: $2 \mathrm{~A}, \mathrm{~B}$ ). For both the plants, it was observed that dry weight and water content increased with the increase in the leaf area depicting that, dry weight and water content showed linear relationship. When these parameters were analyzed for linear regression model, the maximum $\mathrm{R}^{2}$ observed for dry weight was 0.808 followed by water content of 0.806 in $H$. Isora while in $V$. negundo maximum $\mathrm{R}^{2}$ was observed for dry weight being 0.970 followed by water content of 0.966 (Table: 1 ).

Table 1: Results of Regression analysis of helicteres isora L. and Vitex negundo L.

\begin{tabular}{cccc}
\hline Plant name & Parameter & Regression equation & $\mathbf{R}^{2}$ \\
\hline \multirow{2}{*}{ 1. Helicteres isora L. } & $\mathrm{DW}$ & $\mathrm{Y}=3.07 \mathrm{x}-2.247$ & 0.808 \\
\cline { 2 - 4 } & $\mathrm{WC}$ & $\mathrm{Y}=6.219 \mathrm{x}-5.365$ & 0.806 \\
\hline \multirow{2}{*}{ 2. Vitex negundo L. } & $\mathrm{DW}$ & $\mathrm{Y}=7.112 \mathrm{x}+1.699$ & 0.970 \\
\cline { 2 - 4 } & $\mathrm{WC}$ & $\mathrm{Y}=12.89 \mathrm{x}+2.591$ & 0.966 \\
\hline
\end{tabular}
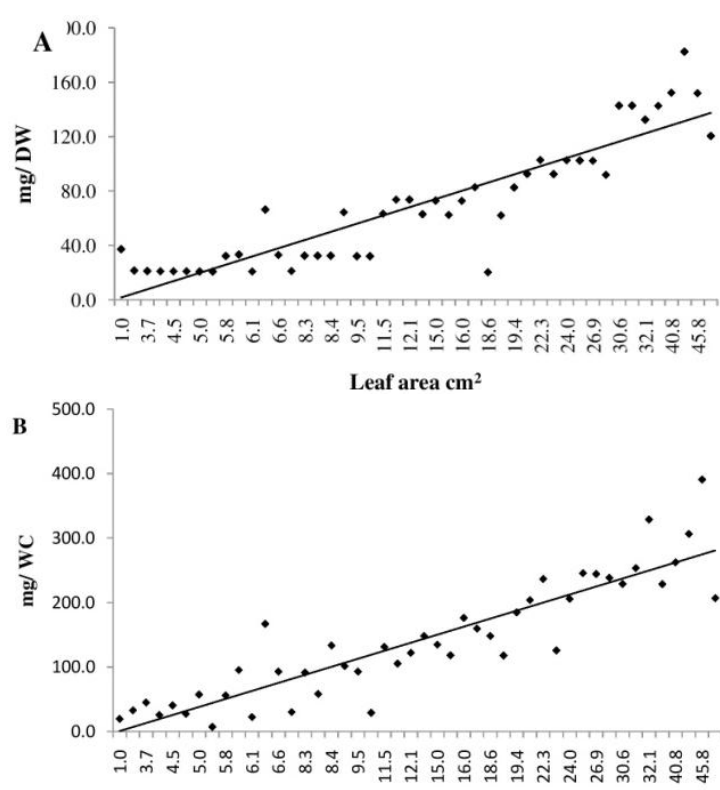

Leaf area $\mathrm{cm}^{2}$

Fig. 1: Leaf area linear model for helicteres isora 1 . using gravimetric parameter (A) dry weight (DW) and (B) water content (WC) of each individual leaf.
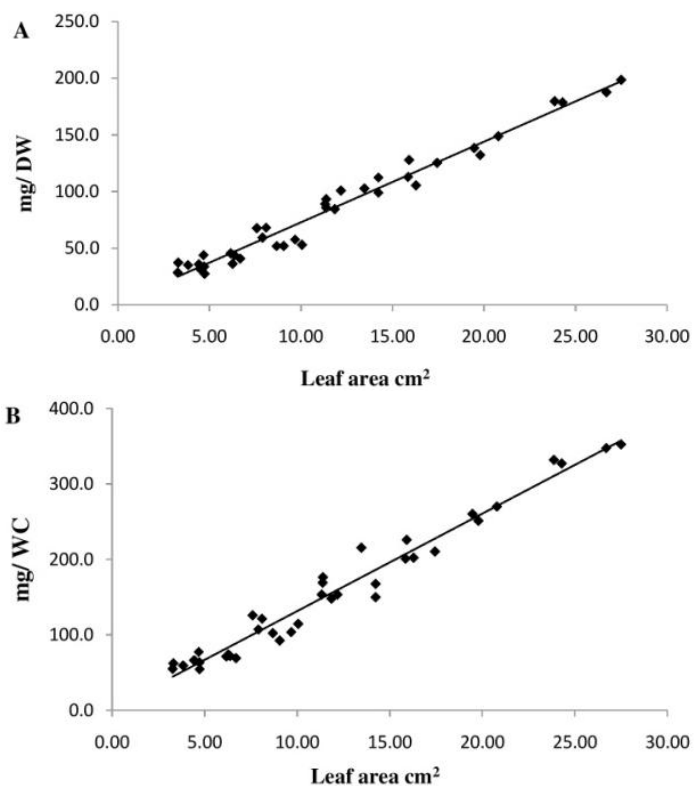

Fig. 2: Leaf area linear model for vitex negundo L. using gravimetric parameter (A) dry weight (DW) and (B) water content (WC) of each individual leaf. 
Over all data on dry weight $\left(\mathrm{R}^{2}=0.808, \mathrm{R}^{2}=0.970\right)$ is better correlated with leaf area and that could be used as a linear model for $H$. isora and $V$. negundo. However, the data on water content were also highly significant at $\mathrm{P} \leq 0.001$, so, water content could also be considered for the linear model development in these plants. Water content is also considered as one of the important parameters to study since in many studies suggests importance of water in expansion growth [13, 14]. It is assumed that the increase in size of the leaf may also increase the water content at least up to certain level, that level at which the leaf size is stabilized. In the present study, we found good correlation with water content and leaf area in $V$. Negundo and $H$. isora. Similar work was also reported for Adhatoda vasica L. [15].

Leaf area is a key variable in study of physiology, horticulture and crop science [16, 17]. It is major parameter in plant modeling studies, to develop physiological models in plant breeding [18]. It plays an important role to determine productivity, development rate, yield potential, radiation use efficiency and water as well as nutrient take-up [19]. Leaf area affects the rates of canopy, gas exchange and energy balance [20].

The plant canopy is a locus of physical and biogeochemical processes in an ecosystem and their functional and structural attributes are affected by microclimatic conditions, nutrient dynamics, herbivore activities and many other factors. The amount of foliage contained in plant canopies is one of the basic ecological characteristic indicating the integrated effect of these factors. In turn, canopy leaf area serves as the dominant control over primary production [21]

This variable represents the amount of leaf material in ecosystems and controls the links between biosphere and atmosphere through various processes such as photosynthesis, respiration, transpiration and rain interception; hence, it is an important property of plants [22]. Leaf area of the plants not only determines the photosynthetic capacity but can be used as a morphological marker for collection of medicinally important materials [8, 9]. In plant pathology, leaf area could be used as an indicator of treatment effectiveness to compare the effect of different diseases on plant types [23]. Leaf area is also required for determination evapotranspiration [24]. In the monitoring of phytomass production and grain yield of cereal crops, leaf area is a key variable [25]. It is an important measurement for understanding rates of energy and materials exchange between forest and atmosphere [26].

An accurate measurement of leaf area is essential for understanding the interaction between crop growth and environment. Many methods have been developed to measure leaf area [27] Although, accurate assessment of leaf area is a critical component in understanding physiological and agronomic process, obtaining leaf area is often costly, time consuming and destructive [28]. Therefore, another simple, inexpensive, rapid, reliable and non destructive method for estimating leaf area is required for the experiments [18]. Thus, we suggest linear model for economically and medicinally important plants. Estimating leaf area from equations using simple measurement of leaf dimension is an inexpensive, rapid and non-destructive alternative for accurately assessing leaf area [29].

Linear models for leaf area measurement are also developed for plant species as a non-destructive method. So the establishment of mathematical and especially linear relationship between leaf area and one of more growth parameters of the leaf is an advantageous way to determine leaf area under field conditions [30], and can be extended for follow up applications like preparation of herbal drugs.

\section{ACKNOWLEDGEMENT}

The authors are thankful to Centre for Advanced Studies in Plant Biotechnology \& Genetic Engineering, State Government for providing lab facilities, Gujarat, India.

\section{Financial support and sponsorship: Nil.}

Conflict of Interests: There are no conflicts of interest.

\section{REFERENCES}

1. Jain A, Sinha P, Desai N. Estimation of flavonoid, phenol content and antioxidant potential of Indian screw tree (Helicteres isora L.). International Journal of Pharmaceutical Science and Drug Research. 2014; 5(4):1320-30.

2. Lee DH, Iwanski GB, Thoennissen NH. Cucurbitacin: ancient compound shedding new light on cancer treatment. The Scientific World Journal. 2010; 10:413-8.

3. Gayathri P, Gayathri DS, Sivagami S, Saroja S. Screening and quantitation of phytochemicals and nutritional components of the fruit and bark of Helicteres isora L. Journal for Drugs and Medicines. 2010; 2(1):57-62.

4. Bean MF, Antoun M, Abramson D, Chang CJ, Mc Laughlin JL, Cassady JM. Cucurbitacin B and Isocucurbitacin B Cytotoxic components of Helicteres isora L. Journal of Natural Product. 1985; 48(3):500-503.

5. Basri F, Sharma HP, Firdaus S, Jain P, Ranjan A. A review of Ethnomedicinal plant-Vitex negundo Linn. International Journal of Advanced Research. 2014; 2:882-894.

6. Ahuja SC, Ahuja S, Ahuja U. Nirgundi (Vitex negundo) - Nature's Gift to Mankind. Asian Agri-History. 2015; 19(1):5-32.

7. Dharmasiri MG, Jayakody JR, Galhena G, Liyanage SSP, Ratnasooriya WD. Anti-inflammatory and analgesic activities of mature fresh leaves of Vitex negundo. Journal of Ethnopharmacology. 2003; 87(2):199-206.

8. Kuvad RP, Chudasama KS, Jhala VM, Thaker VS. Standardization of leaf age for radical scavenging activity in TerminaliaArjuna. Journal of Applied and Natural Science. 2014; 6(1):76-80.

9. Tatmiya RN, Chudasama KS, Jhala VM, Thaker VS. Screening of proper leaf size in Centella asiatica for antioxidant potential and separation of phenolics using RP-HPLC. Journal of Applied Pharmacological Science. 2014; 4 (2):043-047.

10. Daughtry CST. Direct measurement of canopy structure Instrumentation for studying vegetation canopies for remote sensing in optical and thermal infrared regions. Goel MS; Nnorman JM (Ed.) Harwood Academic, New York 1990:45-60.

11. Blanco FF, Folegatti MV. A new method for estimating the leaf area index of cucumber and tomato plants. Horticultura brasileira. 2003; 21(4):666-669.

12. O'Neal ME, Landis DA, RufusI. An inexpensive, accurate method for measuring leaf area and defoliation through digital image analysis. Journal of Economic Entomology. 2002; 95(6):1190-1194.

13. Egli DB, Tekrony DM. Species differences in seed water status during seed maturation and germination. Research journal of seed science. 1997; 7:3-11. 
14. Rabadia VS, Thaker VS, Singh YD. Relationship between water content and growth of seed and fiber of three cotton genotypes. Journal of Agronomy and Crop Science. 1999; 183:255-261.

15. Thaker JV, Kuvad RP, Thaker VS. A linear model for leaf area measurement to screen potential leaf material for herbal drug in Adhatoda vasica L. Journal of Applied and Natural Science. 2016; 8(1):140-143.

16. Cho YY, Oh S, Oh MM, Son JE. Estimation of individual leaf area, fresh weight, and dry weight of hydroponically grown cucumbers (Cucumis sativus L.) using leaf length, width, and SPAD value. Scientiahorticulturae. 2007; 111(4):330-334.

17. Xu R, Dai J, Luo W, Yin X, Li Y, Tai X, Han L, Chen Y, Lin L, Li G, Zou C. A photothermal model of leaf area index for greenhouse crops. Agricultural and Forest Meteorology. 2010; 150(4):541-552.

18. Gao F, Anderson MC, Kustas WP, Wang Y. Simple method for retrieving leaf area index from Landsat using MODIS leaf area index products as reference. Journal of Applied Remote Sensing. 2012; 6(1):063554-1.

19. Olfati JA, Peyvast GH, Shabani H, Nosratie-Rad Z. An estimation of individual leaf area in cabbage and broccoli using non-destructive methods. Journal of Agriculture Science and Technology. 2010; 12:627-632.

20. Wythers KR, Reich PB, Turner DP. Predicting leaf area index from scaling principles: corroboration and consequences, Tree Physiology. 2003; 23:1171-1179.

21. Asner G, Scurlock J, Hicke J. Global synthesis of leaf area index observations: implications for ecological and remote sensing studies. Global Ecology Biogeography 12:191-205.

22. Cournac L, Dubois M, Chave J, Riera B. Fast determination of light availability and leaf area index in tropical forests. Journal of Tropical Ecology. 2002; 18:295-302.

23. Bryson R, Paveley N, Clark W, Bradley R, Scott R. Use of in-field measurements of green leaf area and incident radiation to estimate the effects of yellow rust epidemics on the yield of winter wheat. European Journal of Agronomy. 1997; 7:53-62.
24. Vertessy R, Benyon R, O'sullivan S, Gribben P. Relationships between stem diameter, sapwood area, leaf area and transpiration in a young mountain ash forest. Tree physiology. 1994; 15:559-567.

25. Duchemin B, Maisongrande P, Boulet G, Benhadj I. A simple algorithm for yield estimates: Evaluation for semi-arid irrigated winter wheat monitored with green leaf area index. Environmental modelling \& software. 2007; 23:876-892.

26. Vose J, Sullivan N, Clinton B, Bolstad P Vertical leaf area distribution, light transmittance and application of the Beer-Lambert Law in four mature hardwood stands in the southern Appalachians. Canadian Journal of Forest Research. 1995 ;25:1036-1043.

27. Bhakshandesh E, Kamkar B, Tsialtas J. Application of linear models for estimation of leaf area in Soyabean. Photosynthetica.2011; 49:405-416.

28. Pandey SK, Singh H. A simple, cost-effective method for leaf area estimation. Americal Journal of Botany. 2011.

29. Tsialtas J, Maslaris N Leaf area estimation in a sugar beet cultivar by linear models. Photosynthetica. 2005; 43:47.

30. Lu H, Lu C, Wei M, Chan L. Comparison of Different Models for Nondestructive Leaf Area Estimation in Taro Contribution no. 2125 from TARI. Agronomy Journal. 2004; 96:448-453.

31. Available at: http://btm.gujarat.gov.in/btm/bitvirtual-init.htm

\section{How to cite this article:}

Kumbhani NR, Kuvad RP, Thaker VS. Development of linear model for leaf area measurement of two medicinally important plants: Helicteres isora L. and Vitex negundo L. J App Biol Biotech. 2017; 5 (03): 057-060. DOI: 10.7324/JABB.2017.50310 